\title{
HER2 status in advanced or metastatic gastric, esophageal, or gastro-esophageal adenocarcinoma for entry to the TRIO-013/LOGiC trial of lapatinib
}

Michael F. Press ${ }^{1}$, Catherine E. Ellis ${ }^{2}$, Robert C. Gagnon ${ }^{3 *}$, Tobias J. Grob ${ }^{4}$, Marc Buyse ${ }^{5}$, Ivonne Villalobos ${ }^{1}$, Zhiyong Liang ${ }^{6}$, Shafei Wu ${ }^{6}$, Yung-Jue Bang ${ }^{7}$, Shu-Kui Qin ${ }^{8}$, Hyun Cheol Chung ${ }^{9}$, Jianming $\mathrm{Xu}^{10}$, Joon Oh Park ${ }^{11}$, Krzysztof Jeziorski ${ }^{12}$, Karen Afenjar ${ }^{13}$, Yanling Ma ${ }^{1}$, Monica C. Estrada ${ }^{1}$, Douglas M. Robinson ${ }^{14}$, Stefan J. Scherer ${ }^{14}$, Guido Sauter ${ }^{4}$, J. Randolph Hecht $^{15}$, and Dennis J. Slamon ${ }^{15}$

${ }^{1}$ Norris Comprehensive Cancer Center, University of Southern California, Los Angeles, CA; ${ }^{2}$ GlaxoSmithKline, PA, United States; ${ }^{3}$ Bristol-Myers Squibb Company, Princeton, NJ, USA;

${ }^{4}$ Institute of Pathology, University Medical Center Hamburg-Eppendorf, Hamburg, Germany; ${ }^{5}$ International Drug Development Institute, Leuven, Belgium; ${ }^{6}$ Department of Pathology, Peking Union Medical College Hospital, Chinese Academy of Medical Science, Beijing 100730, P.R.China; ${ }^{7}$ Seoul National University College of Medicine, Seoul, Republic of Korea; ${ }^{8}$ PLA Cancer Center, Nanjing Bayi Hospital, Jiangsu, China; ${ }^{9}$ Yonsei Cancer Center, Yonsei University College of Medicine, Seoul, Korea; ${ }^{10}$ The Affiliated Hospital Cancer Center, Academy of Military Medical Sciences, Beijing, China; ${ }^{11}$ Samsung Medical Center, Sungkyunkwan University School of Medicine, Seoul, Republic of Korea; ${ }^{12}$ Maria SklodowskaCurie Memorial Cancer Centre and Institute of Oncology, Warsaw, Poland; ${ }^{13}$ Translational Research in Oncology, Paris, France; ${ }^{14}$ Novartis Pharmaceutical Corporation, East Hanover, NJ, USA; and ${ }^{15}$ Division of Hematology/Oncology, David Geffen School of Medicine at UCLA, Santa Monica, CA, United States.

Running Title: Lapatinib in HER2-Amplified Upper Gastrointestinal Cancers (MCT Limit: 60 characters)

Key words: human epidermal growth factor receptor type 2 (HER2), HER2 testing, upper gastrointestinal cancers, HER2/ERBB2 gene amplification, lapatinib.

Abbreviations List: CAP, College of American Pathologists; CI, confidence interval; CIRG, Cancer International Research Group; ERBB2, avian erythroblastosis oncogene B2; FISH, fluorescence in situ hybridization; HR, hazard ratio; HER2, human epidermal growth factor receptor 2; IHC, immunohistochemistry; LOGiC, Lapatinib Optimization Study in ErbB2 \{HER2\} Positive Gastric Cancer; OS, overall survival; PEP, primary efficacy population; PFS, progression-free survival; ToGA, Trastuzumab for Gastric Cancer; TRIO, Translational Research In Oncology; UGI, upper gastro-intestinal 
Notes: GlaxoSmithKline; GlaxoSmithKline provided support to Translational Research In Oncology (TRIO) to fund the clinical trial and the central laboratories in order to screen clinical specimens for the trial. The conduct of the clinical trial was determined by the Steering Committee. The decision to analyze this data was made by the Translational Research Committee. Both committees contained minority GlaxoSmithKline representation.

Conflict of Interest Statement and Disclosure: MFPress disclosed serving as a consultant or on an advisory board and receiving honoraria within the last two years from Biocartis, Halozyme, Oncomed, Puma Biotechnology, and Cepheid. His institution received research funding from GlaxoSmithKline, Eli Lilly and Cepheid. CE Ellis and R Gagnon disclosed employment and stock or other ownership with GlaxoSmithKline. M Buyse disclosed employment and stock or other ownership in IDDI. YJ Bang disclosed serving as a consultant or on an advisory board and receiving honoraria and research funding from GlaxoSmithKline and Novartis. I Villalobos has an immediate family member whose institution has received research support from GSK and this immediate family member has also received honoraria within the last two years from GlaxoSmithKline, Puma Biotechnology, and Cepheid. JR Hecht disclosed serving as a consultant or on an advisory board and receiving honoraria from Amgen and Genentech/Roche. JR Hecht also disclosed receiving research funding from GlaxoSmithKline, Gilead, Immunomedics, Celgene, and OncoMed. T Grob, HCChung, Z Liang, S Wu, S Qin, J Xu, JO Park, K Jeziorski, G Sauter and DJ Slamon have no conflict of interest to disclose.

Lapatinib has become the property of Novartis Pharma AG as of March 1, 2015.

Corresponding Author: Michael F. Press, USC / Norris Comprehensive Cancer Center, NOR5409, 1441 Eastlake Avenue, Los Angeles, CA 90033; 323-865-0563, Fax: 323-8650122,press@usc.edu.

Notes about the manuscript:

Abstract: 245 words.

Manuscript text: 4981 words in track changes (MCT limit: 5000 words).

References: 53

Number of Tables: 3

Number of figures: 2

Supplementary Data: text, 1550 words; 7 supplemental tables; and 2 supplementary figures. Portions of this manuscript have been previously presented at the European Society of Medical

Oncology meeting (Concordance study, May 31, 2014) and American Society of Clinical Oncology meeting (October 1, 2013, LOGiC study).

*Robert Gagnon was an employee at GlaxoSmithKline during the time of study conduct and initial publication development. 


\section{Abstract (Word count 245, MCT 250 word limit)}

HER2/ERBB2 status is used to select patients for HER2-targeted therapy. HER2/ERBB2 amplification/overexpression of upper gastrointestinal (UGI) adenocarcinomas was determined locally or in two central laboratories to select patients for the TRIO-013/LOGiC trial of chemotherapy with or without lapatinib. Patients selected locally had central laboratory confirmation of HER2-amplification for inclusion in the primary efficacy population. HER2 was assessed with PathVysion or IQ PharmDx fluorescence in situ hybridization (FISH) and HercepTest immunohistochemistry assays. Associations with outcomes were retrospectively evaluated. Overall, HER2 status was determined in UGI cancers from 4674 patients in a central laboratory for eligibility (1995 cases) and for confirmation of local HER2 results (333 cases). Of 1995 adenocarcinomas screened centrally, 322 (16.1\%) had HER2 amplified disease with 29 (1.5\%) showing HER2 genomic heterogeneity. Men and older patients had higher rates of amplification. Of 545 patients accrued to the trial (gastric, 87.3\%; GEJ, 8.3\% and esophageal cancer, 4.4\%) 487 patients (89\%) were centrally confirmed as having HER2 amplified disease. Concordance between central and local HER2 testing was 83\%. Concordance between PathVysion and IQ PharmDx FISH assays was 99\% and FISH in the two central laboratories was 95\%. Lapatinib-treated Asian participants and those less than 60 years had significant improvement in progression-free survival (PFS), particularly among those whose cancers had 5.01-10.0 and >10.0-fold amplification of HER2. In conclusion, HER2 is commonly amplified in UGI adenocarcinomas with amplification highly correlated to overexpression, and HER2 amplification levels correlated with PFS. While HER2 genomic heterogeneity occurs, its prevalence is low. 


\section{Introduction}

The human epidermal growth factor receptor (EGFR) type 2 (HER2) gene (aka ERBB2) is commonly amplified(1-3) and overexpressed in adenocarcinomas of the stomach, gastroesophageal junction (GEJ) and esophagus and is a potential target for therapeutic intervention. Although the role of HER2 as a prognostic marker in gastric cancer remains an issue of debate, HER2 amplification/overexpression is an important therapeutic target for trastuzumab and is associated with significant improvements in progression-free(PFS) and overall survival(OS)(4). Routine diagnostic testing is now recommended in gastric and GEJ adenocarcinomas based on these findings that led to approval of the drug by the U.S. Food and Drug Administration(FDA)(5) and European Medicines Agency (EMA).

Here we report on assessments of HER2 status conducted for patient entry to a trial of lapatinib, a dual tyrosine kinase inhibitor of HER2 and EGFR, in combination with chemotherapy in patients with advanced HER2-positive upper gastrointestinal(UGI) adenocarcinomas. The TRIO-013/LOGiC study was based on efficacy of lapatinib in HER2positive breast cancer patients(6-9) and activity both in vitro and in vivo with UGI cancer cell lines exhibiting HER2 gene amplification(10). In addition, modest single-agent activity had been observed in patients with UGI cancers. At the time this trial was initiated no anti-HER2 agent had demonstrated activity in a systematic study of this disease. This retrospective study of HER2 gene amplification and overexpression in UGI adenocarcinomas was initiated to explore the potential roles of HER2 amplification levels and HER2 genomic heterogeneity in lapatinib treatment responsiveness, as measured by improved PFS or improved OS in the LOGiC clinical trial. 


\section{Materials and Methods}

TRIO-013/LOGiC clinical trial. The TRIO-013/LOGiC clinical trial (Lapatinib Optimization Study in ErbB2 \{HER2\} Positive Gastric Cancer: A Phase III Global, Blinded Study Designed to Evaluate Clinical Endpoints and Safety of Chemotherapy Plus Lapatinib) was a double-blind, randomized, multi-center, phase III study (ClinicalTrials.gov: NCT00680901) of capecitabine and oxaliplatin (CapeOx) without or with lapatinib conducted in patients with metastatic HER2-positive gastric, GEJ, and esophageal adenocarcinoma between June 2008 and January 2012 at 186 centers in 22 countries. The details of patient accrual, treatment, toxicities and outcomes are described separately(11). Here we describe HER2 testing issues and their associations with outcomes. The study was conducted in accordance with the current ethical principles outlined in the Declaration of Helsinki guidelines(12).

HER2 Status for Enrollment in the TRIO-013/LOGiC clinical trial. Patients enrolled in this trial had advanced, HER2-positive UGI adenocarcinomas as evaluated in local laboratories (Immunohistochemistry $\{\mathrm{IHC}\} 2+$ and fluorescence in situ hybridization (FISH)-amplified, or IHC3+, or FISH-amplified) or in a central laboratory (FISH-amplified). Patients enrolled in the trial with a positive HER2 local test result were required to have tumor tissue submitted to one of two central laboratories for assessment of HER2 gene amplification by the HER2 PathVysion FISH assay (Abbott Molecular, Inc., Des Plaines, Illinois) and expression by IHC (HercepTest, Dako Biotechnology, Carpinteria, CA) for confirmation of the local result. Although patients could be enrolled to the trial based on HER2-positive status in a local laboratory, patient inclusion in the primary efficacy population (PEP) required HER2 gene amplification confirmed by a central laboratory. The PEP was composed of all patients whose tumors were centrally 
determined as HER2-amplified. The primary endpoint was OS in the PEP. PFS was a secondary endpoint.

Conduct of the trial. Patients whose UGI cancers were assessed as HER2-positive by either IHC or in situ hybridization assay and otherwise eligible for the trial(11) were stratified according to history of prior adjuvant or neoadjuvant therapy and region (Asia, North America and rest of the world) then randomized to receive oxaliplatin (130 $\mathrm{mg} / \mathrm{m} 2$ on day one) and capecitabine (850 mg/m2, bid, days 1-14) either with lapatinib (1250 mg daily, day 1-21) or with placebo (daily, day 1-21).

Identification of PEP. As no HER2 tests were approved for use in UGI cancers at the start of the trial, Translational Research In Oncology (TRIO) / Cancer International Research Group (CIRG) selected the PathVysion dual-color FISH assay (HER2 PathVysion FISH assay, Abbott Molecular, Inc.) as the primary method for assessment of HER2-amplification in patients' cancers to establish a consistent standard for HER2-positivity across the trial based on previous approval as a companion diagnostic for breast cancer patient selection to HER2-targeted therapies and experience with this assay method(8, 13-18). Formalin-fixed paraffin-embedded (FFPE) tissues or unstained sections were submitted to a central laboratory for assessment of HER2 status(Figure 1A).

Laboratory Assessment of HER2 status. HER2 amplification was determined by FISH, as described(15-17) (Supplementary Data), in one of two central laboratories, one at the University of Southern California (Los Angeles, California) and the other at the University Medical Center Hamburg-Eppendorf (Hamburg, Germany). The entire processed tissue section was routinely screened for focal areas of carcinoma with HER2 status that differed from the remaining tumor both by IHC and FISH (HER2 genomic heterogeneity). When such areas of disparate HER2 gene 
copy number were identified they were scored separately by FISH and the tumor area estimated. HER2 amplification was defined as a HER2 gene-to-CEP17 ratio of 2.0 or greater, the U.S. FDA-approved ratio; an average HER2 gene copy number of 4.0 or greater was not required(1921). Similarly for IHC, high geographic variability in HER2 immunostaining (e.g. areas of IHC $3+$ and other areas of IHC $0 / 1+$ that are consistent with HER2 genomic heterogeneity) were noted and the percent of each area was estimated (see Figure 2 and Supplementary Figures S1 and S2).

HercepTest IHC Assay. During the conduct of this trial it became apparent, based on reports from ToGA trial investigators $(4,22)$, that there may be some controversy related to HER2 testing in gastric and GEJ adenocarcinomas. Therefore, TRIO/CIRG investigators and the trial sponsor decided to also implement immunohistochemistry (IHC) testing for HER2 protein in the central laboratories. The HercepTest(Dako, Inc.), a companion diagnostic initially approved for breast cancer assessments and subsequently, approved for gastric and GEJ adenocarcinomas, was used to determine HER2 protein expression as described(15-17) and summarized in Supplementary Methods.

Concordance Study. The HER2 PathVysion FISH assay was selected as the primary testing method for assessment of HER2 status; however, during the trial questions were raised about assay comparability with the HER2 IQFISH pharmDx method (Dako Corporation) which became FDA-approved for HER2 testing in gastric cancer for selection of patients to trastuzumab therapy. In order to assess agreement rates between assay methods and agreement rates in the two central laboratories, a separate cohort of 488 UGI adenocarcinoma cases, 419(86\%) gastric, 43(8.8\%) gastroesophageal junction(GEJ), and 26(5.3\%) esophageal cancers, were procured from commercial providers (Asterand Bioscience, Analytical Biological Services, 
Inc., Proteogenex, Inc., Individumed $\mathrm{GmbH}$ ) as FFPE blocks and screened by HercepTest to ensure representation of all four IHC staining intensities (Figure 1B). All IHC3+ and IHC2+ cases were included in the concordance study. Whereas IHC1+ and IHC 0 cases were grouped by primary tumor site (gastric, GEJ and esophageal) with inclusion of all GEJ and esophageal carcinomas, then gastric carcinomas were randomly selected. The 159 selected cases were masked and sent to two central laboratories for HER2 FISH testing, masked to all information.

Data Analyses. Statistical aspects of the LOGIC study design and statistical methods for analyses are summarized elsewhere(11). Briefly, we performed a Cox proportional hazards model on treatment for each of the subgroups to compute a hazard ratio and $95 \%$ confidence interval. Then using the unstratified log rank test, we computed p-values, as well as median survival times and 95\% confidence intervals for both PFS and OS. Although the analyses between FISH results and outcomes reported here are exploratory and hypothesis generating, the differences observed retrospectively in a clinical trial were still considered in our analyses as potentially meaningful, namely, they warrant further exploration in a subsequent study, or not. We chose a $p$-value of $\leq 0.05$ as our threshold to suggest a marker / analysis was meaningful. For concordance analyses, positive percent agreement (PPA), negative percent agreement (NPA) and overall percent agreement (OPA) with 95\% confidence intervals were determined as described(23) and summarized in Supplementary Methods.

\section{Results}

HER2 Testing in the TRIO-013/LOGiC Trial. Overall, 4674 patients were registered in the central database and underwent eligibility screening for the TRIO-013/LOGiC trial(Figure 1A). Central FISH testing was performed in 1995 patients for eligibility and 333 for confirmation of a 
local HER2 result; one patient enrolled and deemed HER2 positive by a local laboratory did not have tumor tissue remaining for central confirmation of HER2 status and FISH results were not obtained from six additional samples(Figure 1A). Of the 1995 carcinomas screened by a central laboratory for trial enrollment, 322(16.1\%) had HER2 amplification(Figure 1A), 29(1.5\%) of which showed HER2 genomic heterogeneity(Figure 2). The adenocarcinomas with genomic heterogeneity represent $9 \%$ of identified HER2-amplified cases primarily screened in the central laboratories. An additional 33 cases with HER2 genomic heterogeneity were identified among those screened in local laboratories and confirmed in a central laboratory. Demographic data for these patients demonstrates a higher frequency of disease among men and shows that men and older patients have higher rates of HER2 gene amplification (Table 1).

In patients whose cancers were centrally assessed, either for primary assessment or confirmation of local laboratory results, HER2 status by both FISH and IHC is known for 1250 with 457/547(83.5\%) amplified cases IHC2+ or IHC3+ and 680/703(96.7\%) non-amplified cases either IHC1+ or IHC0 (Table 2). The overall concordance rate between FISH and IHC results for HER2 status was 91\% (95\% confidence interval $\{\mathrm{CI}\}: 89.2 \%, 92.4 \%)$. In our dataset, there were no cases that were IHC3+/FISH-negative. The majority $(84 \%)$ of IHC2+ cases were HER2 amplified, while relatively few $\operatorname{IHC} 0(\mathrm{n}=33,6 \%)$ or $\operatorname{IHC} 1+(\mathrm{n}=57,26 \%)$ cancers were HER2 amplified(Table 2). The distribution across the various IHC immunostaining categories progressively transitions from predominantly IHC0 (515/703, 73.3\%) without amplification (FISH ratio $<2.0$ ), to a more even distribution (IHC0 $\{18 \%\}, \operatorname{IHC} 1+\{28 \%\}, \operatorname{IHC} 2+\{35 \%\}$, $\mathrm{IHC} 3+\{19 \%\}$ ) with low-level amplification (FISH ratio of 2.0-5.0) to progressively higher distributions of stronger IHC staining ( $\mathrm{IHC} 0\{2 \%\}, \operatorname{IHC} 1+\{6 \%\}, \operatorname{IHC} 2+\{24 \%\}, \operatorname{IHC} 3+\{67 \%\}$ ) 
for FISH ratios $>5.0-10.0$ and the highest distribution $(\mathrm{IHC} 3+\{91 \%\})$ for FISH ratios $>10.0$ (Table 2).

Of 333 patients with trial enrollment based on local laboratory testing, 332 had tumor tissue available for subsequent re-assessment in a central laboratory (Supplementary Table S1). Concordance between central and local HER2 testing was 84.4\% (275/326, Figure 1A). Since samples were not required for re-evaluation in the central laboratory for patients not enrolled to the trial, overall concordance in this population could not be assessed.

The agreement rate between local and central laboratory HER2 testing was dependent on the HER2 testing method used in the local laboratory and concordance varied accordingly. Among the 332 cancers evaluated both locally and centrally, 259 cases were tested in local laboratories by ISH alone, 33 by ISH and IHC, and 40 by IHC alone. Among the 292 cases tested locally by ISH, the central laboratory determined the HER2 gene amplification status in 286 of the cases. HER2 amplified status was confirmed for 250; however, 36 were assessed as not amplified for an ISH concordance rate of 87\% (95\% CI: 83.1\%, 90.8\%)(Supplementary Table S2). Seven cases had been evaluated by CISH in local laboratories and five of the cases were confirmed as amplified by central laboratory FISH. Agreement between local laboratory and central laboratory for HER2 IHC assays was even less (58\%) (Supplemental Supplementary Table S3), although the number of cases analyzed was limited and different assays may have been used locally $(n=73)$.

Concordance Study for Different HER2 FISH assay methods between the two Central Laboratories. Before accrual to the LOGiC trial was complete, the ToGA trial was completed and the FDA, subsequently, approved two companion diagnostic assays, the Dako HercepTest IHC assay (October, 2010) and the Dako HER2 IQFISH pharmDx FISH assay (February, 2013) 
for selection of gastric and GEJ cancer patients to trastuzumab plus chemotherapy(4). Therefore, we performed a concordance study to demonstrate agreement between the PathVysion HER2 FISH assay and the Dako HER2 IQFISH pharmDx HER2 assay (Figure 1B and Supplementary Results and Supplementary Tables S4 and S5). UGI adenocarcinomas from 488 patients who were not enrolled in the TRIO-013/LOGiC trial were used for the concordance studies (Figure 1B). In order to ensure the full spectrum of HER2 expression was more evenly represented in the concordance comparison rather than a predominance of HER2 low-expression, not-amplified cases, the tumors were initially processed and scored by IHC with the selection of 159 cases for further analysis by FISH. The central laboratory was blinded to the prior IHC status during FISH analyses performed in the central laboratories. The initial IHC results from all 488 UGI cancers showed highly variable immunostaining in 17 cases $(3.5 \%)$ that was considered consistent with potential HER2 genomic heterogeneity (Supplementary Figures S1 and S2). The central masking/randomization center included 14 of these IHC-variable cases that had sufficient tumor for inclusion in the concordance study thus increasing the rate of potential "HER2 heterogeneity" from $3.5 \%(17 / 488)$ to $8.8 \%(14 / 159)$. Of the 159 cases selected for inclusion in the concordance study: 31 exhibited HER2 staining indicative of $\mathrm{IHC} 3+, 20 \mathrm{IHC} 2+, 55 \mathrm{IHC} 1+$ and $53 \mathrm{IHC} 0($ Figure 1B).

Overall concordance between LOGiC central laboratories for 151 cases successfully tested by PathVysion HER2 FISH assay in both laboratories was 94.7\% (95\%CI:89.9\%, 97.3\%) with 93.8\% PPA (95\%CI:83.2\%, 97.9\%) and 95.1\% NPA (95\%CI:89.1\%, 97.9\%)(Supplementary Table S5). Discordance between the two central laboratories was primarily related to differences in scoring of 14 samples with highly variable HER2 immunostaining, consistent with HER2 genomic heterogeneity (Supplementary Results, Supplementary Figures S1 and S2). 
Summary of clinical outcomes in the TRIO-013/LOGiC trial. In total, among the 545 patients accrued to the trial, 487 patients had central-laboratory-confirmed HER2 amplified disease to comprise the primary efficacy population (PEP); while 51 had HER2 non-amplified disease and HER2 amplification status was not determined in seven patients (Table 3 and Figure $1 \mathrm{~A})$.

Among the 487 patients with HER2-amplified cancers in the PEP, 424(87.1\%) had gastric, 43(8.8\%) GEJ and 20(4.1\%) esophageal cancers. In the PEP 297 had cancers that were HER2 $\mathrm{IHC} 3+(61 \%), 108$ were IHC2+(22\%), 54 were IHC1+(11\%), 27 were IHC0 (6\%), and one was IHC unknown. As reported separately in detail(11), the LOGiC trial did not meet its primary end-point of a significant improvement in OS among those patients randomized to receive chemotherapy with lapatinib $(\mathrm{HR}=0.91\{95 \% \mathrm{CI}: 0.73,1.12\}, \mathrm{p}$-value $=0.35)$; however, a significant improvement in PFS was observed $(\mathrm{HR}=0.82\{95 \% \mathrm{CI}: 0.68,1.00\}, \mathrm{p}$-value $=0.038)$. Subset analyses demonstrated meaningful improvements in both PFS and OS for selected subsets of patients, such as those accrued in Asian countries and those patients less than 60 years of age at trial enrollment (Table 3 and Supplementary Table S6). Among Asian participants and those less than 60 years of age we observed greater PFS related to higher levels of HER2 gene amplification(Table 3). In the overall trial population ( $>10.0$-fold) as well as among the Asian population (5.01-10.0 and >10.0-fold) and in the population less than 60 years of age the hazard ratio for PFS became more pronounced only at higher levels of HER2 gene amplification ( $>5.0$ 10.0 and $>10.0$ fold)(Table 3 ). HER2 ratio was not associated with OS in the overall population or in the sub-populations analyzed for PFS (Table 3)(p value $>0.05$ ), with the exception of Asian participants whose cancers had 5.01-10.0 HER2 gene amplification levels. 
Among the 81 cases included in the trial with HER2 gene amplification by FISH with only $\mathrm{IHC} / 1+$ for HER2 protein, hazard ratios for PFS were $(\mathrm{HR}=1.12, \mathrm{p}$-value $=0.65)$ and $\mathrm{OS}$ $(\mathrm{HR}=0.91, \mathrm{p}$-value $=0.71)$. In contrast, those patients whose HER2-amplified UGI cancers were also IHC2+/3+ had greater improvement in PFS $(\mathrm{HR}=0.76,\{95 \% \mathrm{CI}: 0.62,0.94\}$, pvalue $=0.0096)$ but not $\mathrm{OS}(\mathrm{HR}=0.86\{95 \% \mathrm{CI}: 0.68,1.09\}, \mathrm{p}$-value $=0.21)$. Among the 148 participants from Asian countries with HER2-amplified/IHC2+/3+ UGI adenocarcinoma, PFS $(\mathrm{HR}=0.59 ; \mathrm{p}$-value $=0.0020)$ and $\mathrm{OS}(\mathrm{HR}=0.60, \mathrm{p}$-value $=0.0108)$ were greatly improved by the addition of lapatinib to chemotherapy. These results were highly intriguing and will be proposed for further prospective assessments in subsequent studies.

\section{Discussion}

Gastric cancer remains the third leading cause of cancer-related mortality in the world(24). Treatment typically involves gastric resection; however, surgery alone is generally only curative for patients with early-stage disease. For patients with advanced resectable disease, survival rates remain poor but are improved by chemotherapy and possibly radiotherapy(25-27).

HER2 amplification/overexpression as a prognostic marker. The majority of gastric cancer studies do not show an association of HER2 status with clinical outcomes in the absence of chemotherapy and/or radiation therapy(28-37); however, studies of patients treated with chemotherapy and/or radiation therapy demonstrate a survival advantage for patients whose gastric cancers lack HER2 gene amplification/overexpression(32, 38-41). An additional large study of patients with adenocarcinomas of the gastric cardia, gastroesophageal junction and esophagus treated by surgical resection (1980-1997) showed no difference in either diseasespecific survival or OS among patients whose cancers had HER2 gene amplification(42). The 
potential role of HER2 as a predictive marker of responsiveness to chemotherapy and radiation therapy is supported by a retrospective analysis of HER2 gene amplification and overexpression in gastric cancers from patients in the INT-0116/SWOG9008 phase III gastric cancer clinical trial comparing surgery alone with surgery and chemotherapy (5-fluorouracil)/radiation therapy(13). Patients whose gastric cancers were HER2-negative and were treated with chemoradiation therapy had a longer disease-free and overall survival than similar patients treated with gastrectomy alone. In contrast, no benefit from chemotherapy and radiation therapy was observed among the subset of patients whose gastric cancers had HER2 amplification/overexpression(13).

HER2 amplification/overexpression as a target for therapy. HER2 amplification/overexpression is an important therapeutic target for trastuzumab in metastatic gastric and gastroesophageal cancer(4), as it is in metastatic breast cancer(9, 18, 43). Both the Trastuzumab for Gastric Cancer (ToGA) and LOGiC trials were initiated because of medical need in gastric/gastroesophageal/esophageal carcinoma, a high HER2 positivity rate and an already established toxicity profile in breast cancer patients. The ToGA clinical trial assessed efficacy and safety of trastuzumab added to capecitabine or fluorouracil and cisplatin chemotherapy for first-line treatment of advanced gastric or gastro-esophageal junction cancers with overexpression of HER2(4). Among patients assigned to chemotherapy with trastuzumab in the ToGA trial, median OS was 13.8 months (95\% CI 12-16) compared with 11.1 months for those assigned to chemotherapy alone (HR $0 \cdot 74 ; 95 \% \mathrm{CI}: 0 \cdot 60-0 \cdot 91 ; \mathrm{p}=0 \cdot 0046)$. In the LOGiC trial the median OS was 12.2 months $(95 \% \mathrm{CI}$ : 10.6, 14.2) for patients assigned to capecitabine and oxaliplatin chemotherapy with lapatinib compared with 10.5 months $(95 \% \mathrm{CI}: 9.0,11.3)$ for patients assigned to chemotherapy and placebo (HR: 0.91 \{95\%CI: $0.73,1.12\}$; $\mathrm{p}=\mathrm{NS})(11)$. 
Although differences in survival among the overall LOGiC trial population were not observed, Asian patients and patients under 60 years of age did show noticeable improvements in OS(44). However, we did not find any systematic difference in HER2 status by either immunohistochemistry or FISH among these subgroups that could account for the differences in outcome.

HER2 testing in UGI cancers. Routine diagnostic HER2 testing is recommended in gastric and GEJ adenocarcinomas based on findings from the ToGA trial that led to regulatory approval of trastuzumab for this indication in 2010. We found a high concordance rate for HER2 gene amplification status determined with two different FISH assays (99\% agreement) and between two different central laboratories when the same FISH assay is used (95\% agreement), even though the comparison samples were enriched for cases with HER2 genomic heterogeneity (8.8\%). Agreement between local laboratory and central laboratory for HER2 FISH assays was only $87 \%$. Agreement between local laboratory and central laboratory for HER2 IHC assays was less $(58 \%)$ (Supplementary Table S3); however, the number of cases available for this analysis was quite limited. Overall agreement between HER2 IHC and FISH assays in the central laboratory was approximately $90 \%, 91 \%$ in the LOGiC clinical trial cases $(n=1250)$ and $88 \%$ in the concordance cohort cases $(n=155)$. The discrepancies identified for HER2 status determined by IHC compared to FISH, as well as disagreements between local and central laboratory testing, have the potential to inappropriately select some patients for HER2 targeted therapy as well as the potential to inappropriately deny other patients such treatment. Our findings suggest this is of particular concern when IHC is used as the primary test, as addressed elsewhere in detail(20).

There has been some concern that UGI endoscopic biopsies may not provide sufficient tissue for adequate identification of all cancers with this alteration. Although we did not have 
both endoscopic biopsy samples and resection specimens from the same patients for a direct case-by-case comparison, our HER2 amplification rates among patients with endoscopic biopsy specimens (18.3\%) compared to patients who had surgical resection specimens $(15.0 \%)$ suggests that endoscopic biopsies are likely to be representative of the HER2 amplification status (Supplementary Results and Supplementary Table S7).

HER2 genomic heterogeneity. HER2 genomic heterogeneity was observed overall in approximately $1 \%-2 \%$ of the UGI adenocarcinomas in this study (Table 1, Figure 2 and Supplementary Figures S1 and S2). The rate did not vary significantly by patient age, gender, country, or anatomical site. Although the total number of these cases identified by the central laboratory was modest ( $n=62), 51$ of the cases were identified in patients who were subsequently randomly assigned to study treatment, 24 to the lapatinib treatment arm and 27 to the control arm, no significant differences were observed in PFS or OS. It should be noted that our definition(15) of HER2 genomic heterogeneity differs from the definition used in CAP guidelines(45).

The definition of HER2 genomic heterogeneity used in the LOGiC trial was the same as used for trials of breast cancer screened in the same two TRIO/BCIRG central laboratories(16) for the BCIRG-005(46), BCIRG-006(8) and BCIRG-007(47) trials. We consider HER2 genomic heterogeneity to exist when at least one geographically defined area of contiguous tumor cells are identified within a cancer that differs from the remaining tumor cells by HER2 amplification status (i.e. HER2 amplified versus HER2 not amplified). This differs from the definition established by the CAP guidelines for breast cancer(45). The CAP criteria do not distinguish or require a geographically defined area but simply that the scores of 20 or more cells have at least $5 \%$ of scored cells with a HER2-to-CEP17 ratio that is $\geq 2.2$ and less than $50 \%$ of the tumor cells have such a ratio. The guidelines state "HER2 genetic heterogeneity $(\mathrm{GH})$ exists if there are 
more than $5 \%$ but less than $50 \%$ of infiltrating tumor cells with a ratio higher than 2.2 ." We also differ from the guidelines in our approach to scoring HER2 heterogeneity. According to the guidelines, "if 20 cells are counted and at least one cell is identified with a HER2/CEP17 signal ratio higher than 2.2, this specimen contains GH. Likewise, if 60 cells are examined and 3 or more cells have a ratio higher than 2.2, HER2 GH is present." Using this definition leads to substantially higher rates of HER2 heterogeneity by FISH ranging from $14 \%$ to $26 \%$ in breast cancers $(48,49)$. However, use of the same definition in gastric cardia, gastroesophageal junction and esophagus adenocarcinomas demonstrated only 20 of $675(2.9 \%)$ have HER2 genetic heterogeneity(42). These studies contrast with our previously reported lower rates $(0.5 \%$ and $1.1 \%)$ in breast cancer $(15,16,21)$ and similarly low rate for UGI cancers reported here. The CAP definition(45) may lead to the inclusion of a number of cases that do not contain any HER2 gene amplification even in a portion of the tumor. For example, we would consider some of the results generated by the CAP definition to reflect inclusion of (scattered) cancer cells in which a proportion of the cells (exceeding 5\%) are in G2- or M-phase of the cell cycle where DNA has been duplicated leading to doubling of the number of copies of HER2 gene but without a doubling of chromosome 17 centrosomes since the centromeres remain fused until late metaphase. These (scattered) individual cells have a HER2 FISH ratio greater than 2.0, are not amplified, but contribute to "genetic heterogeneity" by the CAP definition. These tumor cells are, likely, simply proliferating (Campeau A and Press MF, unpublished data).

As illustrated (Figure 2, Supplementary Figures S1 and S2), we have required that the differing geographic tumor areas be scored separately and that one area of contiguous tumor cells have an overall FISH ratio less than 2.0 and the other area have a ratio greater than 2.0 with distinctly aggregated or clustered HER2 gene signals in the amplified cancer cells. Accordingly, 
62 cases with HER2 genomic heterogeneity were identified in this study with 51 accrued to the trial. Only two of these cases had genomic heterogeneity in a subpopulation of tumor cells representing less than $5 \%$ of the total area of the tumor. A limitation of our estimates of HER2 genomic heterogeneity is that we seldom had more than a single tissue block from the primary carcinoma from which to make these evaluations. Therefore, our frequencies should be considered from this perspective.

Association of Lapatinib responsiveness with HER2 amplification level. In breast cancer clinical trials of lapatinib we have found a relatively uniform hazard ratio for PFS that was independent of HER2 amplification level in HER2-amplified breast cancer patients(15). Only patients whose metastatic disease lacked HER2 amplification (HER2 FISH ratio <2.0) showed no improvement in PFS with lapatinib treatment $(\mathrm{HR}=1.09,95 \% \mathrm{CI}: 0.86-1.37 ; \mathrm{n}=390)$, while patients whose metastatic disease with low-level (2.0-5.5-fold) amplification $(\mathrm{HR}=0.48,95 \% \mathrm{CI}$ : 0.28-0.83; $\mathrm{n}=82)$, moderate $(5.5-7.6-$ fold $)(\mathrm{HR}=0.35,95 \% \mathrm{CI}: 0.18-0.69 ; \mathrm{n}=89)$, high $(7.6-10.1-$ fold $)(\mathrm{HR}=0.58,95 \% \mathrm{CI}: 0.33-1.05 ; \mathrm{n}=87)$ or very high-level $(>10.1$-fold $)$ amplification $(\mathrm{HR}=0.42$, 95\%CI: 0.24-0.74; $\mathrm{n}=88)$ levels all showed improved PFS associated with lapatinib treatment.

In contrast, this trial of lapatinib in UGI cancer patients with advanced disease showed an association between lapatinib treatment and improved PFS only at higher levels of HER2 amplification. In the entire trial population of UGI cancer patients, those without amplification (FISH ratios $<2.0 ; \mathrm{HR}=0.89,95 \% \mathrm{CI}: 0.50-1.59 ; \mathrm{n}=51$ ), with low-level amplification (FISH ratios 2.0-5.0; HR=0.90, 95\%CI: 0.63-1.29; $\mathrm{n}=140$ ) and with moderate-level amplification (FISH ratios 5.01-10.0; $\mathrm{HR}=0.92,95 \% \mathrm{CI}: 0.66-1.28 ; \mathrm{n}=171)$ showed no significant improvement in PFS, while UGI patients whose metastatic cancers had high-level amplification (FISH ratios >10.0; 
$\mathrm{HR}=0.64,95 \% \mathrm{CI}: 0.47-0.88 ; \mathrm{n}=176$ ) showed significant improvements in PFS with lapatinib treatment. Similarly, in the trial population of Asian UGI cancer patients, those whose cancers lacked HER2 amplification (FISH ratios $<2.0 ; \mathrm{HR}=0.99,95 \% \mathrm{CI}: 0.37-2.63 ; \mathrm{n}=21$ ) as well as those whose cancers had low-level amplification (FISH ratios 2.0-5.0; HR=0.77, 95\%CI: 0.441.37; $\mathrm{n}=56$ ) showed no significant PFS improvement, while those whose cancers had moderatelevel amplification (FISH ratios 5.01-10.0; HR=0.62, 95\%CI: 0.66-1.02; $\mathrm{n}=84$ ) and high-level amplification (FISH ratios $>10.0 ; \mathrm{HR}=0.59,95 \% \mathrm{CI}: 0.33-1.04 ; \mathrm{n}=53$ ) showed significant improvements in PFS with lapatinib treatment. Similar observations were made among UGI cancer patients less than 60 years of age at trial entry where only patients whose adenocarcinomas with low-level HER2 amplification did not show improvements in PFS with lapatinib treatment.

Other investigators have reported similar associations between improved clinical outcomes and moderate or high levels of HER2 gene amplification in gastric cancer patients treated with trastuzumab $(50,51)$. In a cohort of 90 patients Gomez-Martin et al. report a mean HER2/CEP17 ratio of 4.7 as the optimal cutoff value discriminating sensitive and refractory patients $(\mathrm{P}=$ 0.005); a ratio of 4.45 as the optimal cutoff for survival $>12$ months $(P=0.005)$, and a ratio of 5.15 as the optimal cut-off for survival $>16$ months $(P=0.004)(50)$. Although there were only 66 patients in the Ock et al study with HER2 gene amplification status determined by FISH, the conclusions were similar(51). Neither of these studies have a control, untreated group to confirm that patients with a HER2/CEP17 ratio less than 4.7 lack significant improvement in outcomes; however, patients whose cancers have ratios more than approximately 5 show improved outcomes compared to those whose cancers have lower levels of gene amplification. These findings are consistent with our own findings of greater benefit among patients whose cancers 
have higher levels of amplification (ratio 5.0-10 and $\geq 10$ ).

The LOGiC trial did not show a significant association with OS(44), while ToGA did(4). LOGiC demonstrated a significant association with PFS but not with the primary end-point of OS. We consider this to be potentially influenced by several issues including 1.) sample size and its influence on statistical power, 2.) differential drug efficacy between lapatinib and trastuzumab and 3.) treatment compliance. Design of the original LOGiC trial was probably slightly underpowered ( $\mathrm{n}=545$ in LOGiC compared to 594 in ToGA), since LOGiC was originally based on PFS as the initial primary end-point, which was later changed to an OS primary end-point. After exclusion of patients whose disease was HER2-not-amplified, the PEP was limited to 487 participants. LOGiC might have benefited from enrollment of additional participants to gain statistical power for an association with OS. Second, the differential in median OS favored the ToGA trial (ToGA: 13.8 versus 11.1 months; compared to LOGiC: 12.2 versus 10.5 months). However, it is unknown what role treatment compliance may have played in the clinical outcomes. LOGiC may have had a lower rate of compliance with experimental drug treatment. In contrast to trastuzumab with the requirement for intravenous administration, lapatinib, an oral medication, was self-administrated by most participants. This introduces the potential for reduced compliance in the lapatinib treatment arm, especially among patients who may have experienced gastrointestinal side-effects. These issues are compounded by our observations, reported here, that HER2 gene amplification levels may impact clinical outcomes.

Finally, we have not analyzed the potential for other concurrent alterations to effect treatment resistance. For example, co-amplification of HER2 and MET is relatively common in esophago-gastric carcinomas $(1,52)$ and is associated with lack of treatment response to either MET kinase inhibitor (crizotinib) or HER2 inhibitor (trastuzumab) treatment but is associated with therapeutic response to combined treatment in patients with advanced esophago-gastric carcinomas(52). 
A comprehensive assessment of genetic alterations in cancers from patients in the LOGiC trial would potentially provide important information about co-occurring alterations associated with HER2 amplification and lack of treatment response.

In summary, HER2 status determined by IHC and FISH was highly correlated in UGI cancers. The prevalence of HER2 gene amplification was slightly higher in UGI cancers from men compared to women and was also higher among older patients. HER2 genomic heterogeneity was relatively infrequent, approximately $1.6 \%$ overall. The level of HER2 amplification was also correlated with responsiveness to lapatinib treatment in UGI cancer patients.

Acknowledgements: The authors would like to thank the patients who enrolled in the trial as well as the TRIO / Cancer International Research Group Investigators who recruited them at each of the clinical sites and staff at those sites that supported the trial (see Supplementary Data). The authors thank Angela Santiago (USC central laboratory), Roberta Guzman (USC central laboratory), Armen Gasparyan (USC central laboratory), Andreas Marx (University of Hamburg central laboratory), Silvia Schnoeger (University of Hamburg central laboratory), Sascha Eghtessadi (University of Hamburg central laboratory), Sina Dietrich (University of Hamburg central laboratory) for technical assistance; as well as Mary-Ann Lindsay (TRIO), Valerie Bee (TRIO), and Henry Taupin (TRIO), Allison Kemner (GSK), Tomomi Kaneko (GSK), Saba Khan-Wasti (GSK), Sherry Wang (GSK) and Yingjie Huang (GSK) Carmen Arenas-Elliott (GlaxoSmithKline, Oncology R\&D, Collegeville, PA) for operational support.

Note. Lapatinib has become the property of Novartis Pharma AG as of March 1, 2015. 
Ethics committee approval. Ethics committees and/or institutional research boards at each clinical site and at each central laboratory approved the study and the research protocols. All study participants signed an informed consent to enroll in the study. 


\section{References}

1. Cancer Genome Atlas Research N. Comprehensive molecular characterization of gastric adenocarcinoma. Nature. 2014;513:202-9.

2. Dulak AM, Stojanov P, Peng S, Lawrence MS, Fox C, Stewart C, et al. Exome and wholegenome sequencing of esophageal adenocarcinoma identifies recurrent driver events and mutational complexity. Nat Genet. 2013;45:478-86.

3. Yoon HH, Sukov WR, Shi Q, Sattler CA, Wiktor AE, Diasio RB, et al. HER-2/neu gene amplification in relation to expression of HER2 and HER3 proteins in patients with esophageal adenocarcinoma. Cancer. 2014;120:415-24.

4. Bang YJ, Van Cutsem E, Feyereislova A, Chung HC, Shen L, Sawaki A, et al. Trastuzumab in combination with chemotherapy versus chemotherapy alone for treatment of HER2-positive advanced gastric or gastro-oesophageal junction cancer (ToGA): a phase 3, open-label, randomised controlled trial. Lancet. 2010;376:687-97.

5. HERCEPTIN ${ }^{\circledR}$ (trastuzumab): Highlights of prescribing information, Available from: http://wwwaccessdatafdagov/drugsatfda_docs/label/2010/103792s52501blpdf. 2010

6. Piccart-Gebhart MJ, Procter M, Leyland-Jones B, Goldhirsch A, Untch M, Smith I, et al. Trastuzumab after adjuvant chemotherapy in HER2-positive breast cancer. The New England journal of medicine. 2005;353:1659-72.

7. Romond EH, Perez EA, Bryant J, Suman VJ, Geyer CE, Jr., Davidson NE, et al. Trastuzumab plus adjuvant chemotherapy for operable HER2-positive breast cancer. The New England journal of medicine. 2005;353:1673-84.

8. Slamon D, Eiermann W, Robert N, Pienkowski T, Martin M, Press M, et al. Adjuvant trastuzumab in HER2-positive breast cancer. The New England journal of medicine. 2011;365:1273-83.

9. Slamon DJ, Leyland-Jones B, Shak S, Fuchs H, Paton V, Bajamonde A, et al. Use of chemotherapy plus a monoclonal antibody against HER2 for metastatic breast cancer that overexpresses HER2. The New England journal of medicine. 2001;344:783-92.

10. Wainberg ZA, Anghel A, Desai AJ, Ayala R, Luo T, Safran B, et al. Lapatinib, a dual EGFR and HER2 kinase inhibitor, selectively inhibits HER2-amplified human gastric cancer cells and is synergistic with trastuzumab in vitro and in vivo. Clinical Cancer Research. 2010;16:1509-19. 
11. Hecht JR BY, Qin SK, Chung HC, Wu JM, Park JO, Jeziorski K, Shparyk Y, Hoff PM, Sobrero A, Salman P, Li J, Protsenko SA, Wainberg Z, Buyse M, Afenjar K, Houe V, Garcia A, Kaneko T, Huang Y, Khan-Wasti S, Santillana S, Press MF, Slamon DJ. . Lapatinib in combination with capecitabine plus oxaliplatin in HER2-positive advanced or metastatic gastric, esophageal, or gastroesophageal adenocarcinoma: (TRIO-13/LOGiC) a randomized phase III trial. . Journal of Clinical Oncology. 2015;in review.

12. World Medical A. World Medical Association Declaration of Helsinki: ethical principles for medical research involving human subjects. JAMA. 2013;310:2191-4.

13. Gordon MA, Gundacker HM, Benedetti J, Macdonald JS, Baranda JC, Levin WJ, et al. Assessment of HER2 gene amplification in adenocarcinomas of the stomach or gastroesophageal junction in the INT-0116/SWOG9008 clinical trial. Ann Oncol. 2013;24:1754-61.

14. Mass RD, Press MF, Anderson S, Cobleigh MA, Vogel CL, Dybdal N, et al. Evaluation of clinical outcomes according to HER2 detection by fluorescence in situ hybridization in women with metastatic breast cancer treated with trastuzumab. Clin Breast Cancer. 2005;6:240-6.

15. Press MF, Finn RS, Cameron D, Di Leo A, Geyer CE, Villalobos IE, et al. HER-2 gene amplification, HER-2 and epidermal growth factor receptor mRNA and protein expression, and lapatinib efficacy in women with metastatic breast cancer. Clinical Cancer Research. 2008;14:7861-70.

16. Press MF, Sauter G, Bernstein L, Villalobos IE, Mirlacher M, Zhou JY, et al. Diagnostic evaluation of HER-2 as a molecular target: an assessment of accuracy and reproducibility of laboratory testing in large, prospective, randomized clinical trials. Clinical Cancer Research. 2005;11:6598-607.

17. Press MF, Slamon DJ, Flom KJ, Park J, Zhou JY, Bernstein L. Evaluation of HER-2/neu gene amplification and overexpression: comparison of frequently used assay methods in a molecularly characterized cohort of breast cancer specimens. Journal of clinical oncology : official journal of the American Society of Clinical Oncology. 2002;20:3095-105.

18. Vogel CL, Cobleigh MA, Tripathy D, Gutheil JC, Harris LN, Fehrenbacher L, et al. Efficacy and safety of trastuzumab as a single agent in first-line treatment of HER2- 
overexpressing metastatic breast cancer. Journal of clinical oncology : official journal of the American Society of Clinical Oncology. 2002;20:719-26.

19. Press MF, Bernstein L, Thomas PA, Meisner LF, Zhou JY, Ma Y, et al. HER-2/neu gene amplification characterized by fluorescence in situ hybridization: poor prognosis in nodenegative breast carcinomas. Journal of clinical oncology : official journal of the American Society of Clinical Oncology. 1997;15:2894-904.

20. Sauter G, Lee J, Bartlett JM, Slamon DJ, Press MF. Guidelines for human epidermal growth factor receptor 2 testing: biologic and methodologic considerations. Journal of clinical oncology : official journal of the American Society of Clinical Oncology. 2009;27:1323-33.

21. Press MF, Villalobos IE, Santiago A, Guzman R, Estrada MC, Gasparyan A, et al. Assessing the new ASCO-CAP Guidelines for HER2 Testing by Fluorescence In Situ Hybridization (FISH): Experience of an Academic Consultation Practice. . Archives of Pathology and Laboratory Medicine 2016;in press.

22. Ruschoff J, Dietel M, Baretton G, Arbogast S, Walch A, Monges G, et al. HER2 diagnostics in gastric cancer-guideline validation and development of standardized immunohistochemical testing. Virchows Arch. 2010;457:299-307.

23. Statistical Guidance on Reporting Results from Studies Evaluating Diagnostic Tests. . 2007.

24. Ferlay J, Soerjomataram I, Dikshit R, Eser S, Mathers C, Rebelo M, et al. Cancer incidence and mortality worldwide: Sources, methods and major patterns in GLOBOCAN 2012. International Journal of Cancer 2015 136:E359-E86.

25. Lee J, Lim do H, Kim S, Park SH, Park JO, Park YS, et al. Phase III trial comparing capecitabine plus cisplatin versus capecitabine plus cisplatin with concurrent capecitabine radiotherapy in completely resected gastric cancer with D2 lymph node dissection: the ARTIST trial. Journal of clinical oncology : official journal of the American Society of Clinical Oncology. 2012;30:268-73.

26. Macdonald JS, Smalley SR, Benedetti J, Hundahl SA, Estes NC, Stemmermann GN, et al. Chemoradiotherapy after surgery compared with surgery alone for adenocarcinoma of the stomach or gastroesophageal junction. The New England journal of medicine. 2001;345:725-30. 
27. Smalley SR, Benedetti JK, Haller DG, Hundahl SA, Estes NC, Ajani JA, et al. Updated analysis of SWOG-directed intergroup study 0116: a phase III trial of adjuvant radiochemotherapy versus observation after curative gastric cancer resection. Journal of clinical oncology : official journal of the American Society of Clinical Oncology. 2012;30:2327-33.

28. Hilton DA, West KP. c-erbB-2 oncogene product expression and prognosis in gastric carcinoma. J Clin Pathol. 1992;45:454-6.

29. Kim MA, Jung EJ, Lee HS, Lee HE, Jeon YK, Yang HK, et al. Evaluation of HER-2 gene status in gastric carcinoma using immunohistochemistry, fluorescence in situ hybridization, and real-time quantitative polymerase chain reaction. Hum Pathol. 2007;38:1386-93.

30. Lee KE, Lee HJ, Kim YH, Yu HJ, Yang HK, Kim WH, et al. Prognostic significance of p53, nm23, PCNA and c-erbB-2 in gastric cancer. Jpn J Clin Oncol. 2003;33:173-9.

31. Marx AH, Tharun L, Muth J, Dancau AM, Simon R, Yekebas E, et al. HER-2 amplification is highly homogenous in gastric cancer. Hum Pathol. 2009;40:769-77.

32. Matsubara J, Yamada Y, Hirashima Y, Takahari D, Okita NT, Kato K, et al. Impact of insulin-like growth factor type 1 receptor, epidermal growth factor receptor, and HER2 expressions on outcomes of patients with gastric cancer. Clinical Cancer Research. 2008;14:3022-9.

33. Reichelt U, Duesedau P, Tsourlakis M, Quaas A, Link BC, Schurr PG, et al. Frequent homogeneous HER-2 amplification in primary and metastatic adenocarcinoma of the esophagus. Mod Pathol. 2007;20:120-9.

34. Sasano H, Date F, Imatani A, Asaki S, Nagura H. Double immunostaining for c-erbB-2 and p53 in human stomach cancer cells. Hum Pathol. 1993;24:584-9.

35. Sorscher SM. Marked response to single agent trastuzumab in a patient with metastatic HER-2 gene amplified rectal cancer. Cancer Invest. 2011;29:456-9.

36. Tateishi M, Toda T, Minamisono Y, Nagasaki S. Clinicopathological significance of cerbB-2 protein expression in human gastric carcinoma. J Surg Oncol. 1992;49:209-12.

37. Yu GZ, Chen Y, Wang JJ. Overexpression of Grb2/HER2 signaling in Chinese gastric cancer: their relationship with clinicopathological parameters and prognostic significance. J Cancer Res Clin Oncol. 2009;135:1331-9. 
38. Allgayer H, Babic R, Gruetzner KU, Tarabichi A, Schildberg FW, Heiss MM. c-erbB-2 is of independent prognostic relevance in gastric cancer and is associated with the expression of tumor-associated protease systems. Journal of clinical oncology : official journal of the American Society of Clinical Oncology. 2000;18:2201-9.

39. Nakajima M, Sawada H, Yamada Y, Watanabe A, Tatsumi M, Yamashita J, et al. The prognostic significance of amplification and overexpression of c-met and c-erb B-2 in human gastric carcinomas. Cancer. 1999;85:1894-902.

40. Park DI, Yun JW, Park JH, Oh SJ, Kim HJ, Cho YK, et al. HER-2/neu amplification is an independent prognostic factor in gastric cancer. Dig Dis Sci. 2006;51:1371-9.

41. Yonemura Y, Ninomiya I, Yamaguchi A, Fushida S, Kimura H, Ohoyama S, et al. Evaluation of immunoreactivity for erbB-2 protein as a marker of poor short term prognosis in gastric cancer. Cancer research. 1991;51:1034-8.

42. Yoon HH, Shi Q, Sukov WR, Lewis MA, Sattler CA, Wiktor AE, et al. Adverse prognostic impact of intratumor heterogeneous HER2 gene amplification in patients with esophageal adenocarcinoma. Journal of clinical oncology : official journal of the American Society of Clinical Oncology. 2012;30:3932-8.

43. Cobleigh MA, Vogel CL, Tripathy D, Robert NJ, Scholl S, Fehrenbacher L, et al. Multinational study of the efficacy and safety of humanized anti-HER2 monoclonal antibody in women who have HER2-overexpressing metastatic breast cancer that has progressed after chemotherapy for metastatic disease. Journal of clinical oncology : official journal of the American Society of Clinical Oncology. 1999;17:2639-48.

44. Hecht JR, Bang YJ, Qin SK, Chung HC, Wu JM, Park JO, et al. Lapatinib in combination with capecitabine plus oxaliplatin in HER2-positive advanced or metastatic gastric, esophageal, or gastroesophageal adenocarcinoma: (TRIO-013/LOGiC) a randomized phase III trial. Journal of clinical oncology : official journal of the American Society of Clinical Oncology. 2016;34:443-51.

45. Vance GH, Barry TS, Bloom KJ, Fitzgibbons PL, Hicks DG, Jenkins RB, et al. Genetic heterogeneity in HER2 testing in breast cancer: panel summary and guidelines. Arch Pathol Lab Med. 2009;133:611-2.

46. Eiermann W, Pienkowski T, Crown J, Sadeghi S, Martin M, Chan A, et al. Phase III study of doxorubicin/cyclophosphamide with concomitant versus sequential docetaxel as 
adjuvant treatment in patients with human epidermal growth factor receptor 2-normal, node-positive breast cancer: BCIRG-005 trial. Journal of clinical oncology : official journal of the American Society of Clinical Oncology. 2011;29:3877-84.

47. Valero V, Forbes J, Pegram MD, Pienkowski T, Eiermann W, von Minckwitz G, et al. Multicenter phase III randomized trial comparing docetaxel and trastuzumab with docetaxel, carboplatin, and trastuzumab as first-line chemotherapy for patients with HER2gene-amplified metastatic breast cancer (BCIRG 007 study): two highly active therapeutic regimens. Journal of clinical oncology : official journal of the American Society of Clinical Oncology. 2011;29:149-56.

48. Ohlschlegel C, Zahel K, Kradolfer D, Hell M, Jochum W. HER2 genetic heterogeneity in breast carcinoma. J Clin Pathol. 2011;64:1112-6.

49. Chang MC, Malowany JI, Mazurkiewicz J, Wood M. 'Genetic heterogeneity' in HER2/neu testing by fluorescence in situ hybridization: a study of 2,522 cases. Mod Pathol. 2012;25:683-8.

50. Gomez-Martin C, Plaza JC, Pazo-Cid R, Salud A, Pons F, Fonseca P, et al. Level of HER2 gene amplification predicts response and overall survival in HER2-positive advanced gastric cancer treated with trastuzumab. Journal of clinical oncology : official journal of the American Society of Clinical Oncology. 2013;31:4445-52.

51. Ock CY, Lee KW, Kim JW, Kim JS, Kim TY, Lee KH, et al. Optimal Patient Selection for Trastuzumab Treatment in HER2-Positive Advanced Gastric Cancer. Clinical Cancer Research. 2015;21:2520-9.

52. Kwak EL, Ahronian LG, Siravegna G, Mussolin B, Godfrey JT, Clark JW, et al. Molecular Heterogeneity and Receptor Coamplification Drive Resistance to Targeted Therapy in MET-Amplified Esophagogastric Cancer. Cancer Discovery. 2015;5:1271-81.

53. Catenacci DV, Liao WL, Zhao L, Whitcomb E, Henderson L, O'Day E, et al. Massspectrometry-based quantitation of Her2 in gastroesophageal tumor tissue: comparison to IHC and FISH. Gastric cancer. 2015. 
Author Manuscript Published OnlineFirst on November 3, 2016; DOI: 10.1158/1535-7163.MCT-15-0887 Author manuscripts have been peer reviewed and accepted for publication but have not yet been edited.

Table 1. Demographic information for 1995 * patients whose cancers were assessed initially for HER2 status in the central laboratories for eligibility.

\begin{tabular}{|c|c|c|c|c|c|}
\hline Characteristic & $\begin{array}{c}\text { HER2- } \\
\text { amplified }\end{array}$ & $\begin{array}{c}\text { HER2-not- } \\
\text { amplified }\end{array}$ & $\begin{array}{l}\text { HER2 Genomic } \\
\text { Heterogeneity }\end{array}$ & Totals & $\begin{array}{l}\text { P- } \\
\text { value** }\end{array}$ \\
\hline \multicolumn{5}{|l|}{ Age (years) } & \multirow{9}{*}{0.0038} \\
\hline$\leq 39 \quad(\mathrm{n}=92)$ & $11(11.9 \%)$ & $80(87 \%)$ & $1(1.1 \%)$ & 92 & \\
\hline $40-49 \quad(n=224)$ & $29(12.9 \%)$ & $192(85.8 \%)$ & $3(1.3 \%)$ & 224 & \\
\hline $50-59(\mathrm{n}=529)$ & $75(14.2 \%)$ & $449(84.9 \%)$ & $5(0.9 \%)$ & 529 & \\
\hline $60-69(n=585)$ & $105(17.9 \%)$ & $471(80.6 \%)$ & $9(1.5 \%)$ & 585 & \\
\hline $70-79 \quad(n=320)$ & $63(19.7 \%)$ & $246(76.9 \%)$ & $11(3.4 \%)$ & 320 & \\
\hline$\geq 80 \quad(\mathrm{n}=27)$ & $9(33 \%)$ & $18(67.0 \%)$ & $0(0 \%)$ & 27 & \\
\hline NA $(n=30)$ & 1 & 29 & 0 & 30 & \\
\hline Total: & $293(16.2 \%)$ & $1485(82.2 \%)$ & $29(1.6 \%)$ & 1807 & \\
\hline Gender & & & & & \\
\hline Male $(n=1207)$ & $211(17.5 \%)$ & $974(80.7 \%)$ & $22(1.8 \%)$ & 1207 & \multirow{4}{*}{0.0262} \\
\hline Female $(\mathrm{n}=592)$ & $82(13.9 \%)$ & $503(85 \%)$ & $7(1.1 \%)$ & 592 & \\
\hline NA $(n=8)$ & 0 & 8 & 0 & 8 & \\
\hline Total: & $293(16.2 \%)$ & $1485(82.2 \%)$ & $29(1.6 \%)$ & 1807 & \\
\hline \multicolumn{6}{|l|}{ Country of Origin } \\
\hline Brazil & $41(18.1 \%)$ & $177(78.0 \%)$ & $9(3.9 \%)$ & 227 & \\
\hline Canada & $8(13.6 \%)$ & $50(84.7 \%)$ & $1(1.7 \%)$ & 59 & \\
\hline Chile & $22(16.2 \%)$ & $113(83.1 \%)$ & $1(0.7 \%)$ & 136 & \\
\hline Estonia & $8(14.3 \%)$ & $48(85.7 \%)$ & 0 & 56 & \\
\hline Hong Kong & $4(22.2 \%)$ & $14(77.8 \%)$ & 0 & 18 & \\
\hline Hungary & $9(13.6 \%)$ & $56(84.8)$ & $1(1.5)$ & 66 & \\
\hline Israel & $5(13.2 \%)$ & $33(86.8 \%)$ & 0 & 38 & \\
\hline Italy & $23(20.7 \%)$ & $87(78.4 \%)$ & $1(0.9 \%)$ & 111 & \\
\hline Korea & $2(18.2 \%)$ & $9(81.8 \%)$ & 0 & 11 & \\
\hline Mexico & $4(9.5 \%)$ & $37(88.1 \%)$ & $1(2.4 \%)$ & 42 & \\
\hline Netherlands & $4(28.6 \%)$ & $7(50 \%)$ & $3(21.4 \%)$ & 14 & \\
\hline Peru & $4(21.1 \%)$ & $14(73.7 \%)$ & $1(5.3 \%)$ & 19 & \\
\hline Poland & $52(17.1 \%)$ & $250(82.2 \%)$ & $2(0.7 \%)$ & 304 & \\
\hline Russia & $29(20.6 \%)$ & $111(78.7 \%)$ & $1(0.7 \%)$ & 141 & \\
\hline Taiwan & 0 & 1 & 0 & 1 & \\
\hline Thailand & $1(4.5 \%)$ & $19(86.4 \%)$ & $2(9.1 \%)$ & 22 & \\
\hline Turkey & $3(14.3 \%)$ & $18(85.7 \%)$ & 0 & 21 & \\
\hline United States & $11(23.4 \%)$ & $35(74.5 \%)$ & $1(2.1 \%)$ & 47 & \\
\hline Ukraine & $62(13.1 \%)$ & $406(85.7 \%)$ & $6(1.2 \%)$ & 474 & \\
\hline Totals: $\mathrm{n}=1807$ & & & & 1807 & \\
\hline
\end{tabular}


*Of 1995 cases centrally assessed for HER2 status, a FISH result was not available for analysis in188 of the cases. **P-value was determined using Chi-sqare statistical test. It should also be noted that many Asian sites used a local laboratory, e.g. in China, and provided tissue sections in the central laboratory only for confirmation of their status (primary efficacy population) after accrual to the trial (see Figure 1A). NA, not available. 
Table 2. TRIO-013/LOGiC Clinical Trial: Comparison of HER2 testing by FISH and IHC in two central laboratories.

\begin{tabular}{|c|c|c|c|c|c|c|}
\hline & & \multicolumn{4}{|c|}{ Herceptest IHC score } & \multirow[b]{2}{*}{ Totals } \\
\hline & & $\begin{array}{c}\text { IHC 0 } \\
\text { n }\end{array}$ & $\begin{array}{c}\text { IHC } 1+ \\
n\end{array}$ & $\begin{array}{c}\text { IHC 2+ } \\
\text { n }\end{array}$ & $\begin{array}{c}\text { IHC 3+ } \\
\text { n }\end{array}$ & \\
\hline \multirow{4}{*}{$\begin{array}{l}\text { PathVysion } \\
\text { FISH assay }\end{array}$} & HER2 not ampl & $515(94 \%)$ & $165(74.3 \%)$ & $23(16 \%)$ & 0 & 703 \\
\hline & HER2 amplif* & $33(6 \%)$ & $57(25.7 \%)$ & $121(84 \%)$ & $336(100 \%)$ & 547 \\
\hline & Totals & 548 & 222 & 144 & 336 & 1250 \\
\hline & & \multicolumn{4}{|c|}{ Herceptest IHC score } & \\
\hline \multirow{7}{*}{$\begin{array}{l}\text { PathVysion } \\
\text { FISH assay }\end{array}$} & FISH Ratios & IHC 0 & IHC 1+ & IHC 2+ & IHC 3+ & Totals \\
\hline & $<2.0$, n (\%) & $515(73 \%)$ & $164(23 \%)$ & $24(3 \%)$ & $0(0 \%)$ & 703 \\
\hline & $2.0-5.0$, n (\%) & $29(18 \%)$ & $45(28 \%)$ & $57(35 \%)$ & $31(19 \%)$ & 162 \\
\hline & $\begin{array}{c}>5.0-10.0, n \\
(\%)\end{array}$ & $4(2 \%)$ & $12(6 \%)$ & $45(24 \%)$ & $124(67 \%)$ & 185 \\
\hline & $>10.0$, n $(\%)$ & $0(0 \%)$ & $1(<1 \%)$ & $18(9 \%)$ & $181(91 \%)$ & 200 \\
\hline & & 548 & 222 & 144 & 336 & 1250 \\
\hline & & & & & & \\
\hline
\end{tabular}

Of the 547 HER2 amplified UGI adenocarcinomas 90 (16.5\%) had only IHC 0 or $1+$ immunostaining for HER2 protein.

Overall agreement between FISH and IHC results for HER2 status was 91\% (1,137/1250)(95\% confidence interval: $89.2 \%, 92.4 \%$ ). Other investigators have reported lower concordance rates between IHC and FISH, especially in the IHC 2+ group where less than $40 \%$ have been HER2 amplified by FISH, in esophageal / GE junction or gastric adenocarcinomas $(3,53)$.

*For the 1250 cases with results summarized here HER2 genomic heterogeneity was identified in 69 cases $(4.1 \%)$ as follows by IHC group:

Among IHC 0 there were 5 cases $(0.9 \%)$ showing HER2 genomic heterogeneity. Among IHC $1+$ there were 4 cases $(1.8 \%)$ showing HER2 genomic heterogeneity. Among IHC 2+ there were 13 cases (9\%) showing HER2 genomic heterogeneity. Among IHC $3+$ there were 39 cases (11.6\%) showing HER2 genomic heterogeneity. All 61 cases were tabulated as "HER2 amplified"; IHC was not available for one case with HER2 genomic heterogeneity demonstrated with FISH. 
Table 3. Correlation of PFS and OS with Responsiveness to Lapatinib in the TRIO-013 Trial for Central-Laboratory-Determined HER2 Gene Amplification Status ${ }^{\#}$.

\begin{tabular}{|c|c|c|c|c|c|}
\hline \multicolumn{6}{|c|}{ All Trial Participants } \\
\hline HER2 Status & Number* & $\begin{array}{c}\text { PFS, } \\
\text { HR }(95 \% \text { CI })\end{array}$ & $\begin{array}{c}\text { PFS, Non- } \\
\text { stratified log- } \\
\text { rank, P-value }\end{array}$ & OS, HR (95\% CI) & $\begin{array}{c}\text { OS, Non- } \\
\text { stratified log- } \\
\text { rank, P-value }\end{array}$ \\
\hline Negative & 51 & $0.88(0.48,1.59)$ & 0.6628 & $1.02(0.54,1.92)$ & 0.9617 \\
\hline Positive (PEP) & 487 & $0.81(0.67,0.99)$ & 0.0350 & $0.88(0.71,1.09)$ & 0.2319 \\
\hline FISH Ratios & Number & PFS, HR (95\% CI) & P-value & OS, HR (95\% CI) & OS, P-value \\
\hline$<2.0$ & 51 & $0.89(0.49,1.61)$ & 0.6868 & $1.04(0.55,1.20)$ & 0.9172 \\
\hline $2.0-5.0$ & 140 & $0.89(0.62,1.28)$ & 0.5439 & $0.94(0.64,1.39)$ & 0.7559 \\
\hline $5.01-10.0$ & 171 & $0.92(0.66,1.28)$ & 0.6124 & $0.89(0.62,1.30)$ & 0.5556 \\
\hline$>10.0$ & 176 & $0.62(0.45,0.86)$ & 0.0033 & $0.86(0.61,1.21)$ & 0.3742 \\
\hline & 538* & & & & \\
\hline \multicolumn{6}{|c|}{ Asian Trial Participants } \\
\hline HER2 Status & Number & HR (95\% CI) & P-value & OS, HR (95\% CI) & OS, P-value \\
\hline Negative & 21 & $1.00(0.37,2.70)$ & 0.9794 & $1.33(0.47,3.72)$ & 0.5995 \\
\hline Positive & 193 & $0.66(0.49,0.90)$ & 0.0080 & $0.68(0.48,0.96)$ & 0.0261 \\
\hline FISH Ratios & Number & HR $(95 \%$ CI $)$ & P-value & OS, HR (95\% CI) & OS, P-value \\
\hline$<2.0$ & 21 & $1.00(0.37,2.70)$ & 0.9794 & $1.33(0.47,3.72)$ & 0.5995 \\
\hline $2.0-5.0$ & 56 & $0.77(0.44,1.35)$ & 0.3616 & $0.81(0.43,1.52)$ & 0.5149 \\
\hline $5.01-10.0$ & 84 & $0.62(0.38,1.01)$ & 0.0511 & $0.56(0.33,0.97)$ & 0.0375 \\
\hline$>10.0$ & 53 & $0.57(0.32,1.00)$ & 0.0479 & $0.77(0.42,1.44)$ & 0.4191 \\
\hline Total & 214 & & & & \\
\hline \multicolumn{6}{|c|}{ Trial Participants $<60$ years of age } \\
\hline HER2 Status & Number & HR $(95 \% \mathrm{CI})$ & P-value & OS, HR (95\% CI) & OS, P-value \\
\hline Negative & 28 & $0.43(0.18,1.01)$ & 0.0494 & $0.49(0.20,1.22)$ & 0.1210 \\
\hline Positive & 236 & $0.57(0.44,0.76)$ & $<0.0001$ & $0.69(0.51,0.93)$ & 0.0141 \\
\hline FISH Ratios & Number & HR(95\% CI) & P-value & OS, HR (95\% CI) & OS, P-value \\
\hline$<2.0$ & 28 & $0.43(0.18,1.02)$ & 0.0494 & $0.51(0.20,1.26)$ & 0.1381 \\
\hline $2.0-5.0$ & 64 & $0.73(0.43,1.24)$ & 0.2436 & $0.67(0.37,1.18)$ & 0.1626 \\
\hline $5.01-10.0$ & 81 & $0.57(0.35,0.93)$ & 0.0224 & $0.59(0.34,1.02)$ & 0.0566 \\
\hline$>10.0$ & 91 & $0.42(0.26,0.68)$ & 0.0003 & $0.81(0.51,1.30)$ & 0.3844 \\
\hline Total & 264 & & & & \\
\hline
\end{tabular}

${ }^{\#}$ Findings for the primary endpoint overall survival (OS) are also reported elsewhere (Hecht et al, JCO 34(5): 443-51, 2016);findings for progression-free survival (PFS) are reported here. *The HER2 FISH status was not confirmed for 7 patients enrolled in the trial (see Figure 1A). **Analyses for participants from the rest of the world and participants $\geq 60$ years of age are included in Supplementary Table S6.

HR, hazard ratio; PEP, primary efficacy population; ITTP, intent to treat population. 


\section{Figure Legends}

Figure 1. Schematic diagrams illustrating disposition of TRIO-013/LOGiC and UGI Cancer Concordance Cohort. (A.) HER2 testing in the TRIO-013/LOGiC trial. Patients' gastric, GE junction or esophageal adenocarcinomas were evaluated by FISH assay for HER2 status primarily either in a central laboratory $(\mathrm{N}=1,995)$ or initially in a local laboratory $(\mathrm{N}=2,678)$ followed by central laboratory re-evaluation of those cancers considered to be HER2-positive in the local laboratory $(\mathrm{N}=333)$ for $H E R 2$ gene amplification status. (B.) Specimen selection process for the concordance study in the central laboratories of HER2 testing by FISH to ensure representation of GEJ and esophageal adenocarcinomas. The UGI Cancer Concordance Cohort was composed of 488 UGI adenocarcinomas initially screened by the HER2 HercepTest to identify subgroups with strong (IHC $3+$ ), moderate (IHC 2+), weak (IHC 1+) and absent (IHC 0) HER2 immunostaining. Adenocarcinomas originating from all three anatomical sites (esophagus, gastro-esophageal junction and stomach) are represented in each IHC immunostaining category (see Supplementary Table S4). ${ }^{1}$ One case was excluded as no tumor tissue was identified; sufficient variability in HER2 immunostaining was noted in 17 cases to suggest the possibility of "HER2 genomic heterogeneity".

Figure 2. HER2 genomic heterogeneity. (A.) Low power photomicrograph of a gastric carcinoma with highly variable HER2 immunostaining that demonstrates geographically distinguishable regions of high (IHC 3+) and low (IHC 0) immunohistochemical staining. Two regions, one with high (IHC 3+)(left box) and one with low (IHC 0)(right box) levels of HER2 immunostaining, are identified. 
Original magnification: 40x. (B. and C.) The two boxed areas from A are illustrated at higher magnification, one (B) showing HER2 overexpression (IHC $3+$ ) and the other (C) showing low HER2 expression (IHC 0). Original magnification: 400x. (D. and E.) Fluorescence in situ hybridization (FISH) of HER2 gene copies (red) and chromosome 17 centromeres (green) of the same two regions showing HER2 gene amplification (D) in the region with IHC 3+ immunostaining and a LACK of HER2 gene amplification (E) in the region with IHC 0 immunostaining. Original magnification: 1000x. TRIO013/LOGiC case number 595. 
Figure 1

A. HER2 testing in the TIRO-013/LOGIC trial.

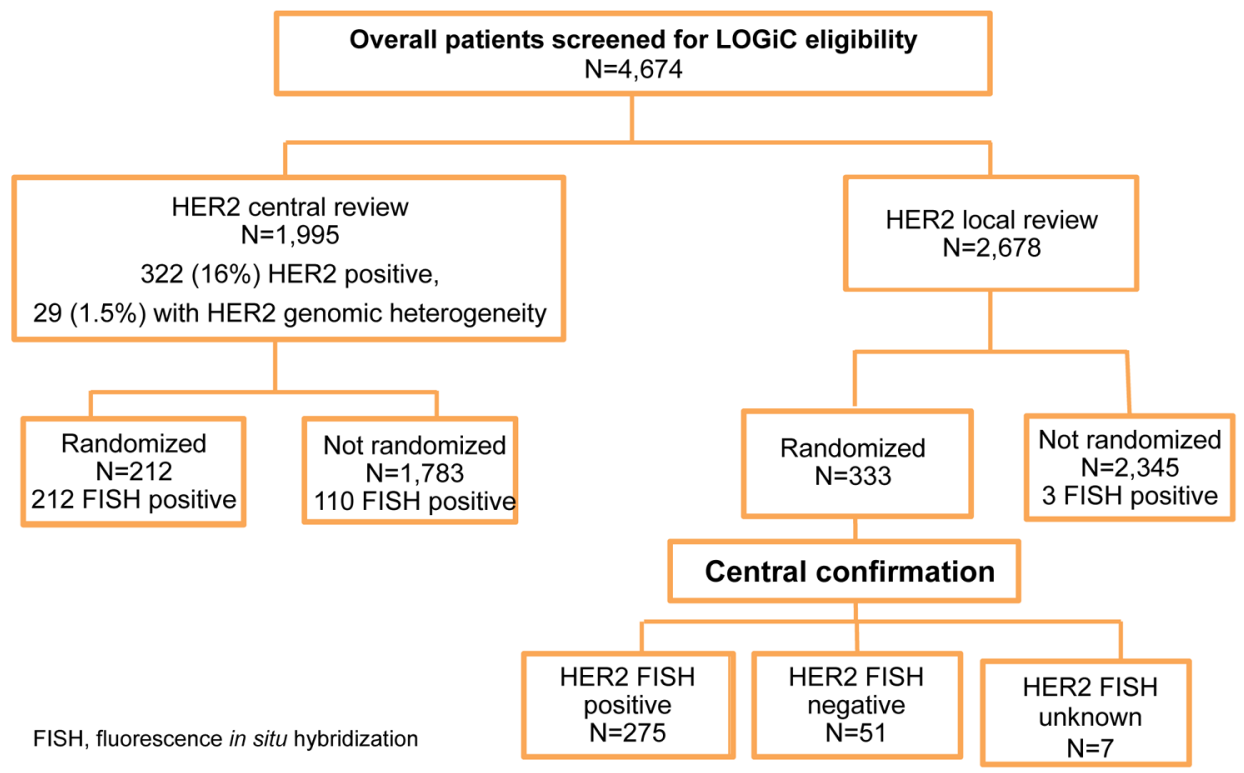

B. Specimen selection process for the HER2 concordance study in Central Laboratories

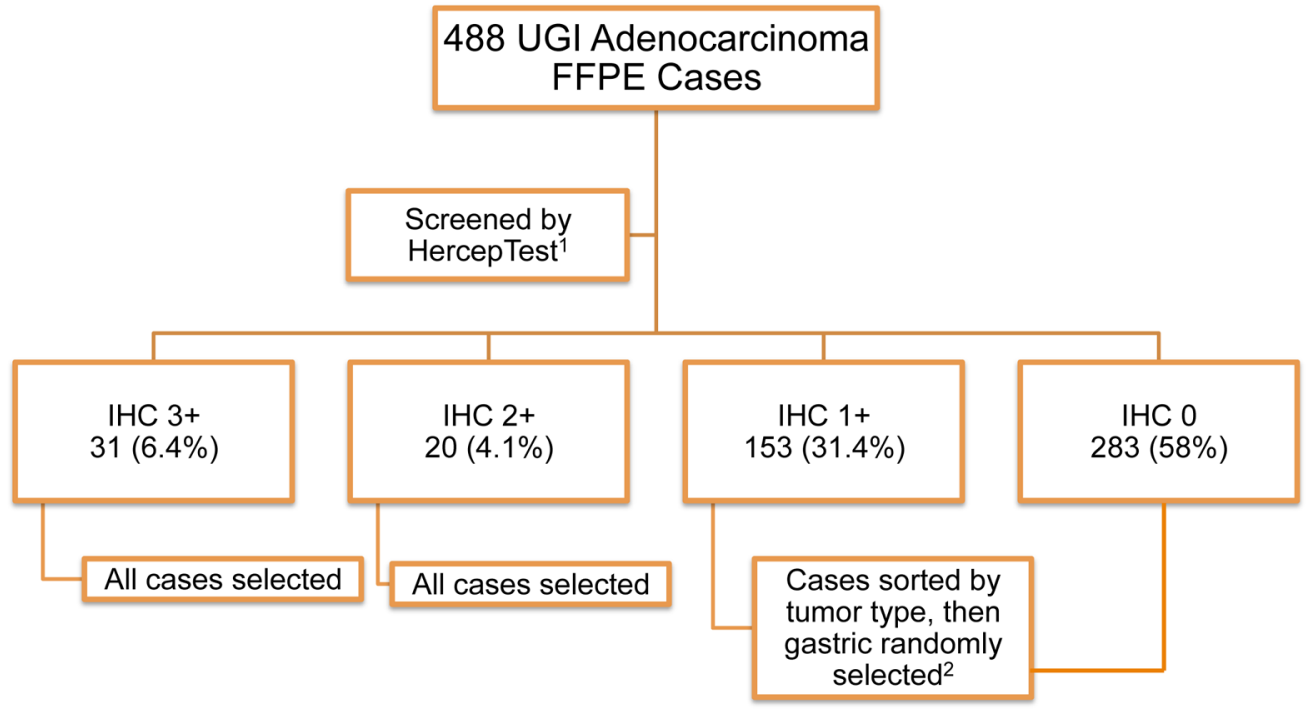


Author Manuscript Published OnlineFirst on November 3, 2016; DOI: 10.1158/1535-7163.MCT-15-0887

Author manuscripts have been peer reviewed and accepted for publication but have not yet been edited.

\section{Figure 2. HER2 genomic heterogeneity}

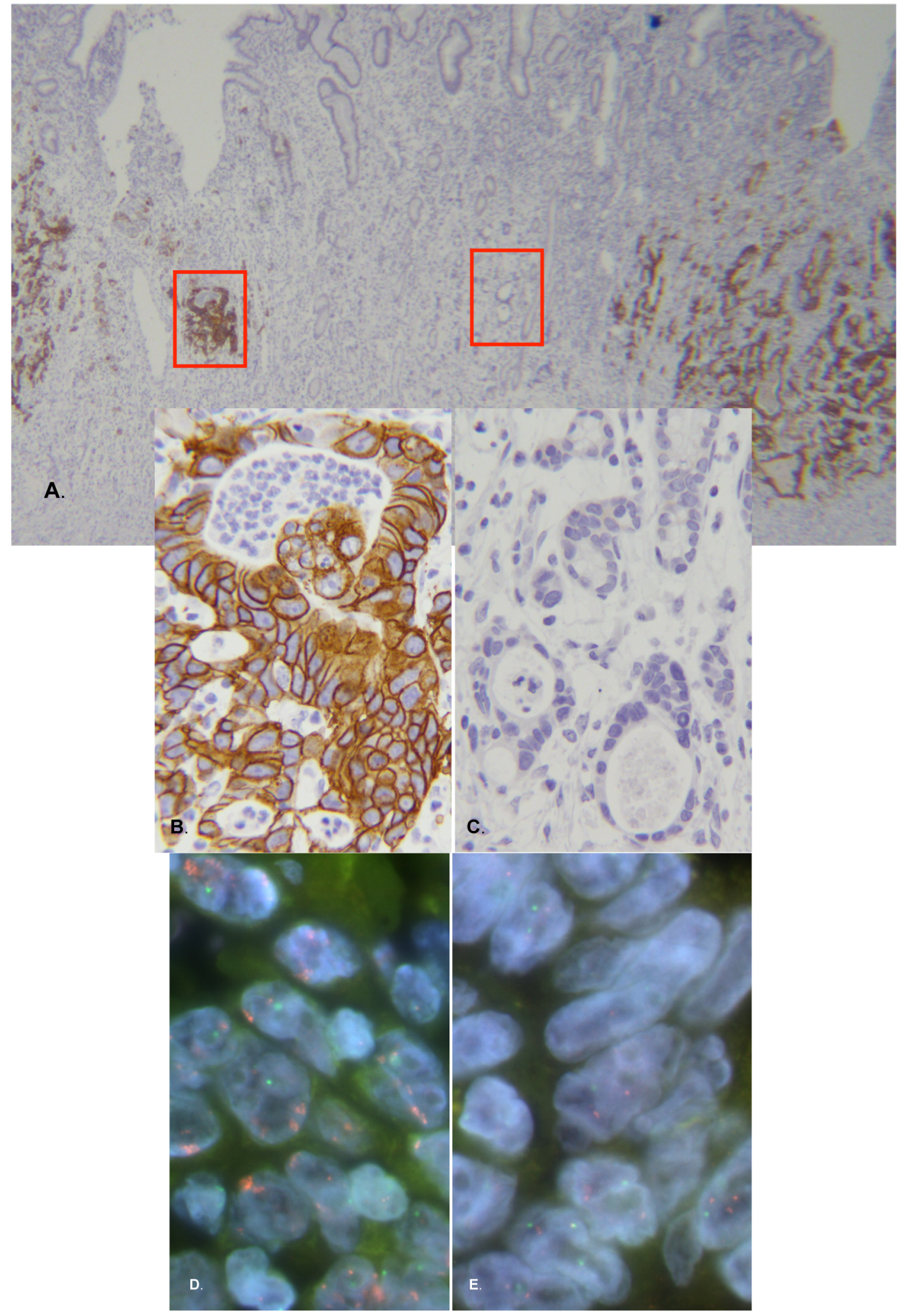




\section{Molecular Cancer Therapeutics}

\section{HER2 status in advanced or metastatic gastric, esophageal, or gastro-esophageal adenocarcinoma for entry to the TRIO-013/LOGiC trial of lapatinib}

Michael F. Press, Catherine E. Ellis, Robert C. Gagnon, et al.

Mol Cancer Ther Published OnlineFirst November 3, 2016.

Updated version Access the most recent version of this article at: doi:10.1158/1535-7163.MCT-15-0887

Supplementary Access the most recent supplemental material at:

Material http://mct.aacrjournals.org/content/suppl/2016/11/03/1535-7163.MCT-15-0887.DC1

Author Author manuscripts have been peer reviewed and accepted for publication but have not yet been Manuscript edited.

E-mail alerts Sign up to receive free email-alerts related to this article or journal.

Reprints and To order reprints of this article or to subscribe to the journal, contact the AACR Publications Subscriptions Department at pubs@aacr.org.

Permissions To request permission to re-use all or part of this article, use this link http://mct.aacrjournals.org/content/early/2016/11/03/1535-7163.MCT-15-0887. Click on "Request Permissions" which will take you to the Copyright Clearance Center's (CCC) Rightslink site. 